PREPARED FOR THE U.S. DEPARTMENT OF ENERGY, UNDER CONTRACT DE-AC02-76CH03073

PPPL-3952

PPPL-3952

UC-70

Initial Operation of the NSTX Fast Tangential

Soft X-Ray Camera

by

B.C. Stratton, R. Feder, S. von Goeler,

G.F. Renda, J.L. Lowrance and V.J. Mastrocola

May 2004

$\left.\stackrel{M}{M}\right|_{\substack{\text { PRInCETON PLASIMA } \\ \text { PHYSICS LABORATORY }}} ^{D}$

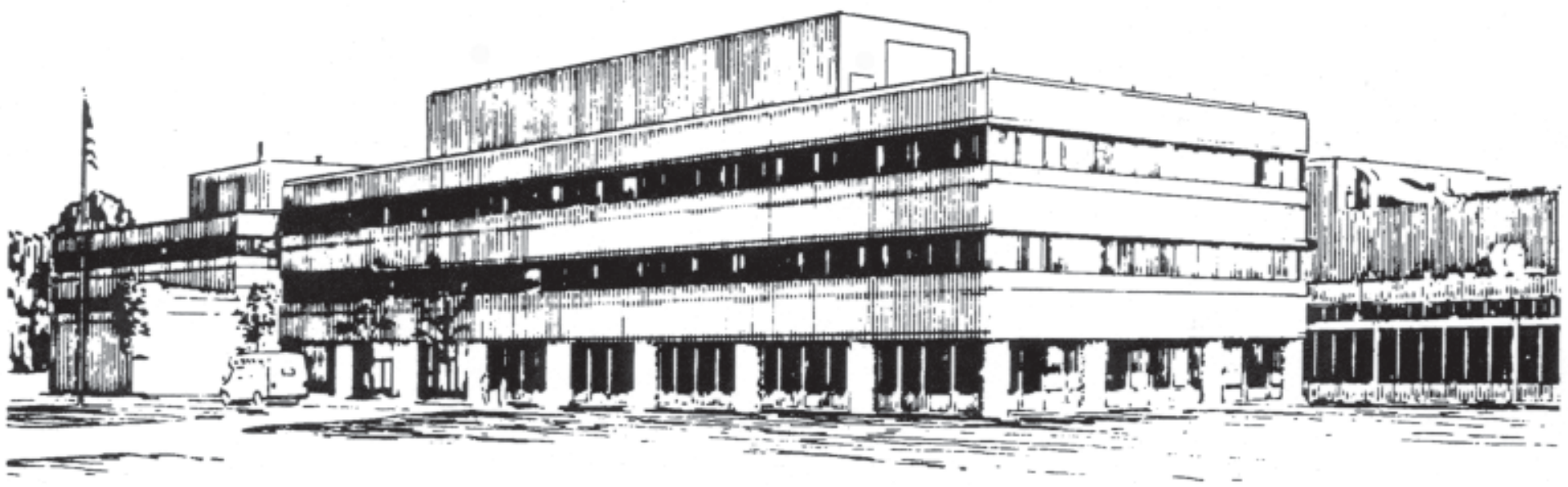

PRINCETON PLASMA PHYSICS LABORATORY PRINCETON UNIVERSITY, PRINCETON, NEW JERSEY 


\section{PPPL Reports Disclaimer}

This report was prepared as an account of work sponsored by an agency of the United States Government. Neither the United States Government nor any agency thereof, nor any of their employees, makes any warranty, express or implied, or assumes any legal liability or responsibility for the accuracy, completeness, or usefulness of any information, apparatus, product, or process disclosed, or represents that its use would not infringe privately owned rights. Reference herein to any specific commercial product, process, or service by trade name, trademark, manufacturer, or otherwise, does not necessarily constitute or imply its endorsement, recommendation, or favoring by the United States Government or any agency thereof. The views and opinions of authors expressed herein do not necessarily state or reflect those of the United States Government or any agency thereof.

\section{Availability}

This report is posted on the U.S. Department of Energy's Princeton Plasma Physics Laboratory Publications and Reports web site in Fiscal Year 2004. The home page for PPPL Reports and Publications is: http://www.pppl.gov/pub_report/

DOE and DOE Contractors can obtain copies of this report from:

U.S. Department of Energy

Office of Scientific and Technical Information

DOE Technical Information Services (DTIS)

P.O. Box 62

Oak Ridge, TN 37831

Telephone: (865) 576-8401

Fax: (865) 576-5728

Email: reports@adonis.osti.gov

This report is available to the general public from:

National Technical Information Service

U.S. Department of Commerce

5285 Port Royal Road

Springfield, VA 22161

Telephone: $1-800-553-6847$ or

(703) $605-6000$

Fax: (703) 321-8547

Internet: http://www.ntis.gov/ordering.htm 


\title{
Initial Operation of the NSTX Fast Tangential Soft X-Ray Camera
}

\author{
B. C. Stratton, R. Feder, and S. von Goeler \\ Princeton Plasma Physics Laboratory, P. O. Box 451, Princeton, NJ 08543 \\ G. F. Renda, V. J. Mastrocola, and J. L. Lowrance \\ Princeton Scientific Instruments, Inc., 7 Deer Park Drive, Monmouth Junction, NJ 08852
}

\begin{abstract}
Fast, two-dimensional, soft x-ray imaging is a powerful technique for the study of MHD instabilities in tokamak plasmas. We have constructed an ultra-fast frame rate soft x-ray camera for the National Spherical Torus Experiment. It is based on a recently developed 64 x 64 pixel CCD camera capable of capturing 300 frames at up to 500,000 frames per second. A pinhole aperture images the plasma soft $\mathrm{x}$-ray emission $(0.2-10 \mathrm{keV})$ onto a P47 scintillator deposited on a fiber-optic faceplate; the scintillator visible light output is detected and amplified by a demagnifying image intensifier and lens-coupled to the CCD chip. A selection of beryllium foils provides discrimination of low-energy emission. The system is installed on NSTX with a wide-angle tangential view of the plasma. Initial plasma data and an assessment of the system performance are presented.
\end{abstract}

\section{INTRODUCTION}

Soft $\mathrm{X}$-ray (SXR) imaging is a powerful technique for the study of magnetohydrodynamic (MHD) instabilities in magnetically confined toroidal plasmas. It is usually performed with one-dimensional arrays of discrete silicon diodes viewing the plasma in a poloidal cross section. Such arrays yield two-dimensional information on the MHD mode structure when the plasma is rotating faster than the frequency of the instabilities of interest. Another approach, which has been used on the TEXTOR tokamak and the LHD stellarator, is to do two-dimensional imaging in the SXR region using a fast camera with a wide-angle toroidal view ${ }^{1-3}$. This approach has the potential advantage that very fast events, (such as sawtooth crashes), stationary MHD modes, and modes with high poloidal mode number can be observed ${ }^{1}$. However, the challenge is to construct a system with sufficient sensitivity that useful images can be obtained at frame rates of 100 $\mathrm{kHz}$ or more.

We have constructed an ultra-fast frame rate soft x-ray pinhole camera for the National Spherical Torus Experiment (NSTX). The system was completed and began operation in February 2004. This paper describes the system, efficiency and noise estimates, and presents some initial data.

\section{EXPERIMENTAL ARRANGEMENT}

A schematic of the fast tangential SXR pinhole camera is shown in figure 1. (Details are given by Feder, et al. ${ }^{4}$ ) SXR photons pass through the pinhole and are converted to visible photons by a fast ( $80 \mathrm{~ns}$ decay time) P47 scintillator deposited on a fiber optic faceplate. A P47 layer thickness of $3.2 \mathrm{mg} / \mathrm{cm}^{2}$ with a $50 \mathrm{~nm}$ aluminum overcoat is used to optimize efficiency for x-ray energies in the 1-6 keV range. Approximately $55 \%$ of the soft x-ray photons are absorbed at $6 \mathrm{keV}$, with more absorption at lower energies. A selection of five pinholes with diameters in the $1-5 \mathrm{~mm}$ range and beryllium foils with 
thicknesses in the 2.5-127 $\square \mathrm{m}$ range are mounted on three remotely-controlled linear motion vacuum feedthroughs. Changing the pinhole diameter allows the signal or optical throughput to be optimized. Varying the beryllium foil thickness changes the cutoff energy of the transmitted x-ray photons. Visible photons emitted by the scintillator are transmitted by the fiber-optic-faceplate to an electrostatic image intensifier, which demagnifies the image by $6: 1$ to match the scintillator diameter $(80 \mathrm{~mm})$ to the size of the CCD chip $(13.3 \mathrm{~mm} \times 13.3 \mathrm{~mm})$. The image intensifier demagnifies the image more efficiently than is possible with a lens system. A pair of $\mathrm{f} / 0.95$ lenses operating at near unity magnification efficiently couples the image from the intensifier output to the CCD chip. Because the diameter of the individual fibers in the fiber optic faceplates is much smaller than the pixel dimensions, any cross talk between fibers has a negligible effect on the image quality. The image intensifier is very sensitive to magnetic fields so it is enclosed in a three-layer magnetic shield ${ }^{4}$.

The ultra-fast CCD camera is the model PSI-5 produced by Princeton Scientific Instruments, Inc. It utilizes a unique CCD chip design to allow frame rates of up to 500 $\mathrm{kHz}$ for 300 frames. This is achieved by storing all 300 frames on the CCD chip and then performing a standard slow (10 seconds) CCD readout into a control and data acquisition PC. The camera produces $64 \times 64$ pixel images and the dimensions of the light-sensitive area of each pixel are $202 \square \mathrm{m} \times 62 \square \mathrm{m}$. The pixels have a full-well capacity of 50,000 electrons and the readout noise is 46 electrons. Digitization is at 14 bits with a transfer function of 3.05 electrons per digitizer count.

The camera may be operated in either pre-trigger mode or in post-trigger mode. In pretrigger mode, the camera takes 300 images after receiving a trigger pulse at a preset time during the discharge. In post-trigger mode, the camera operates in a streaming mode with the most recent 300 frames of data always present on the chip; the camera stops acquiring new frames when the trigger pulse is received. The post-trigger mode will be useful for MHD studies because the occurrence time of individual MHD events cannot be reliably predicted. The post-trigger will be obtained from a soft x-ray diode or Mirnov coil using a transient signal detection circuit. The camera is operated by a local PC which acts as a server for a web interface that can be accessed from another computer using a web browser. This makes remote control of the system convenient.

The camera has a wide angle $\left(28^{\circ}\right)$ tangential view of the NSTX plasma, as shown in figure 2. Space limitations did not allow the optical axis to be placed in the NSTX midplane so it is tilted downward at a $7^{\circ}$ angle. This provides a view of nearly the entire plasma diameter and most of the vertical extent of the plasma. There is slight vignetting of the field of view by the top and bottom of the port structure. The entire diagnostic is heavy due to the weight of the magnetic shielding, and it will become heavier when lead and borated polyethylene radiation shielding is implemented to reduce neutron and gamma noise seen by the CCD camera. Thus, it is supported by a large, rigid support structure $^{4}$.

\section{SYSTEM SENSITIVITY AND NOISE ESTIMATES}

The overall sensitivity of the system is estimated to be $1.7 \mathrm{CCD}$ photoelectrons per one $\mathrm{keV} \mathrm{x}$-ray photon. The contribution of the individual system components to the system sensitivity is given in Table I. The quantum efficiency of the P47 scintillator as coated was measured using a $\mathrm{Fe}^{55}$ source to be $6 \%$ at $5.9 \mathrm{keV} \mathrm{x}$-ray energy. Using this 
value and the fact that the peak of the P47 emission occurs at $410 \mathrm{~nm}, 20$ visible photons are produced per $1 \mathrm{keV}$ input x-ray energy. We assume that $75 \%$ of the visible photons emitted by the scintillator layer are collected by the fiber optic faceplate. The fiber optic faceplate coupling efficiency of $50 \%$ assumes two coupled fiber optic faceplates with a numerical aperture of 1 . The lens coupling efficiency is calculated assuming two f/0.95 lenses at unity magnification. The image intensifier gain and the CCD quantum efficiency given in Table I are measured values.

These numbers allow us to estimate the noise on the signal for various values of the $\mathrm{x}$ ray flux incident on the scintillator area $\left(0.45 \mathrm{~mm}^{2}\right)$ that corresponds to one pixel. The statistical noise is determined by the number of photoelectrons produced in the input photocathode of the image intensifier, which has a quantum efficiency of $11.5 \%$. The relevant values for noise estimates are: 0.9 intensifier photoelectrons per $1 \mathrm{keV}$ x-ray photon incident on the scintillator, and 2.0 intensifier photoelectrons per photoelectron in a CCD pixel. Using these values and the overall sensitivity of the system, we find that one pixel saturates at $\sim 30,0001 \mathrm{keV}$ x-ray photons incident on the scintillator and the signal-to-noise ratio at this signal level is 160 , determined by signal statistics. At $9800 \mathrm{x}-$ ray photons/pixel, or $1 / 3$ of saturation, the readout noise equals the statistical noise. At higher signal levels, the noise is dominated by statistics, while readout noise dominates at lower signal levels. A signal-to-noise ratio of one occurs at $90 \mathrm{x}$-ray photons/pixel, or $0.5 \%$ of saturation. Thus, the system has a large useful dynamic range, although large signals are required to produce statistics-dominated noise. This could be improved by reducing the readout noise of the CCD chip or by increasing the scintillator quantum efficiency.

\section{EXAMPLES OF DATA}

In this section we show two examples of images from NSTX discharges, one taken at $20 \mathrm{kHz}$ frame rate and the other at $100 \mathrm{kHz}$ frame rate. A $3 \mathrm{~mm}$ diameter pinhole and 7.6 $\square \mathrm{m}$ beryllium foil were used in both cases. The data were taken by triggering the camera at a preset time, as it is not yet setup to use post-trigger mode. Note that two $1 \mathrm{keV} x$-rays incident on the scintillator area equivalent to the sensitive area of one pixel produce one digitizer count.

Figure 3 shows an image obtained at a frame rate of $20 \mathrm{kHz}$ immediately before an internal reconnection event (IRE), a large sawtooth-like event common in NSTX discharges ${ }^{5}$. The signal is large $(\sim 12,000$ digitizer counts/pixel in the most intense part of the image) and the image has low noise. The core $\mathrm{x}$-ray emission drops significantly during the IRE. This is illustrated in figure 4, which compares the time evolution of the signal in a pixel (row 12, column 35) in the most intense part of the image with the signal from a soft $x$-ray diode with a radial view in the plasma midplane. It is clear that the signals are very similar.

It is desirable to study individual MHD events such as IREs at frame rates of $100 \mathrm{kHz}$ or higher if the signal levels are sufficient. This is difficult when operating in pre-trigger mode because 300 frames correspond to a short time window at high frame rates and IREs do not occur at reproducible times. (Post-triggering of the camera will be implemented in the near future.) Thus, we do not yet have images of an IRE at a frame rate higher than $20 \mathrm{kHz}$. As an example of operation at higher frame rates, figure 5 shows an image obtained at $100 \mathrm{kHz}$ frame rate. The peak signal is lower $(\sim 550$ digitizer 
counts/pixel) than in the previous case but the image quality should still be useful for MHD studies.

The images shown in figures 3 and 5 are not well centered on the CCD chip. This is due in part to a misalignment of the chip with respect to the image intensifier that has been corrected since these data were taken. However, even with good alignment, the plasma image is shifted from the center of the CCD chip in both the vertical and horizontal directions. This may be due to the effect on the intensifier of the residual magnetic field inside the magnetic shield. We are working to correct this problem.

In conclusion, we have demonstrated that good quality SXR images can be obtained at high frame rates. We plan to begin studies of MHD phenomena once commissioning of the system is complete.

\section{ACKNOWLEDGEMENTS}

We thank D. Johnson and M. Ono for their support of this project. J. Gorman and D. LaBrie provided invaluable technical help. We thank D. Stutman and K. Tritz of The Johns Hopkins University for the use of the SXR diode data. This work was supported by DOE contract no. DE-AC02-76-CH0-3073. Development of the camera was also supported by DOE contract DOEFX-112497-1 under government prime contract DEFG02-97ER8463.

\section{REFERENCES}

1. S. von Goeler, et al., Rev. Sci. Instrum. 70, 599 (1999).

2. S. Ohdachi, et al., Rev. Sci. Instrum. 72, 724 (2001).

3. S. Ohdachi, et al., Rev. Sci. Instrum. 74, 2136 (2003).

4. R. Feder, et al., $20^{\text {th }}$ IEEE/NPSS Symposium on Fusion Engineering (SOFE), (October 14-17, 2003, San Diego, CA), paper: P2-26-FEDER

5. I. Semenov, et al., Phys. Plasmas 10, 644 (2003). 


\section{FIGURE CAPTIONS}

FIG. 1. Schematic of the fast tangential SXR pinhole camera.

FIG. 2. Horizontal field of view of fast tangential SXR pinhole camera.

FIG. 3. Image taken at at $20 \mathrm{kHz}$ frame rate.

FIG. 4. Time evolution of signal in SXR camera core pixel (dashed line) during internal reconnection event with SXR diode signal (solid line) shown for comparison.

FIG. 5. Image taken at $100 \mathrm{kHz}$ frame rate. 
Table I. Efficiency of System Components

\begin{tabular}{|l|l|}
\hline P47 phosphor & 20 visible photons/1 keV x-ray photon \\
\hline $\begin{array}{l}\text { Scintillator emission collection } \\
\text { efficiency }\end{array}$ & 0.75 \\
\hline Fiber optic faceplate coupling loss & 0.5 \\
\hline Intensifier gain & 5.4 output photons/ input photon \\
\hline Lens transmission & 0.277 \\
\hline CCD quantum efficiency at $410 \mathrm{~nm}$ & 0.5 \\
\hline CCD fill factor & 0.305 \\
\hline Overall sensitivity & $\mathbf{1 . 7}$ CCD photoelectrons/1 keV x-ray photon \\
\hline
\end{tabular}




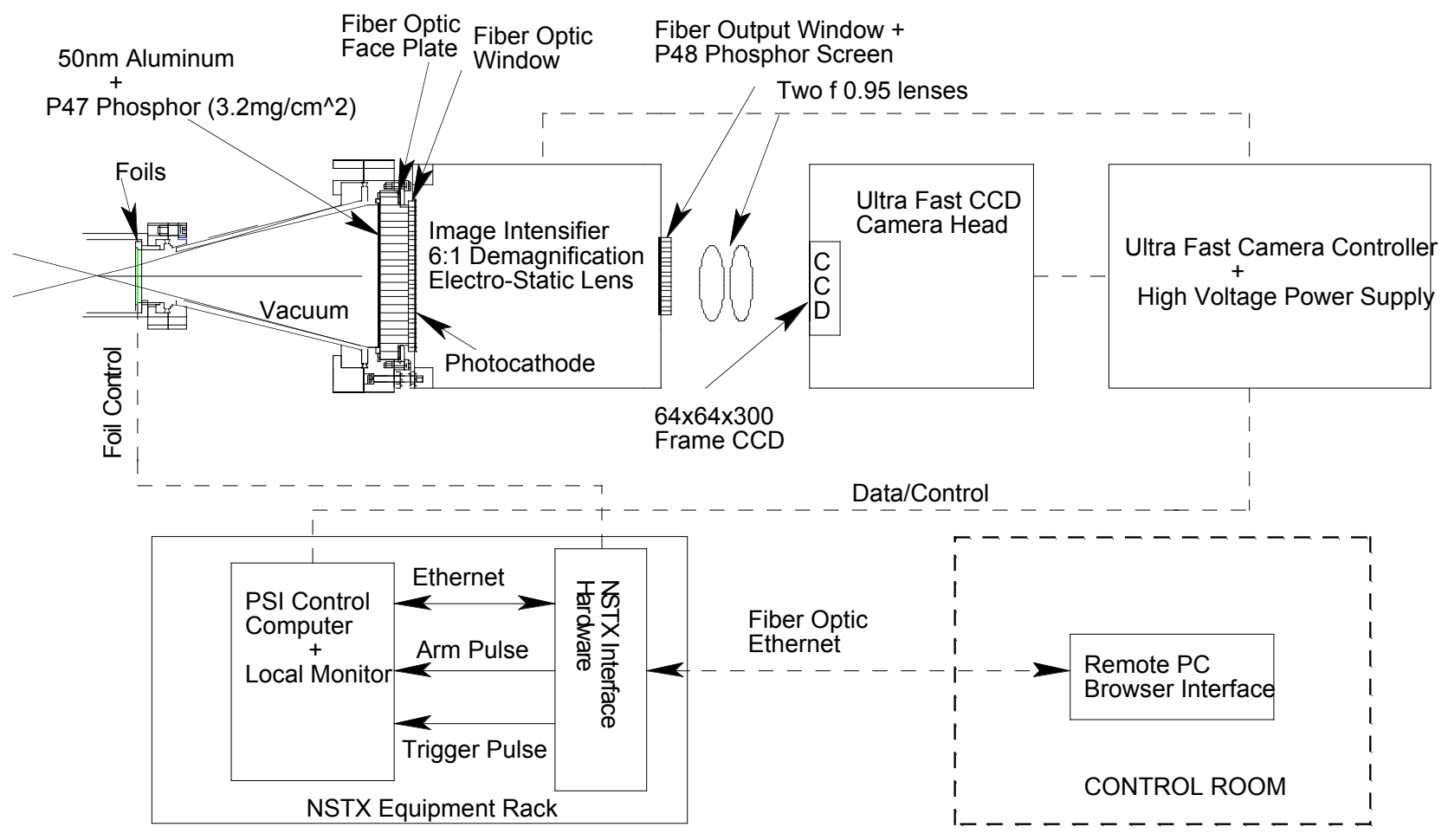

FIG. 1 


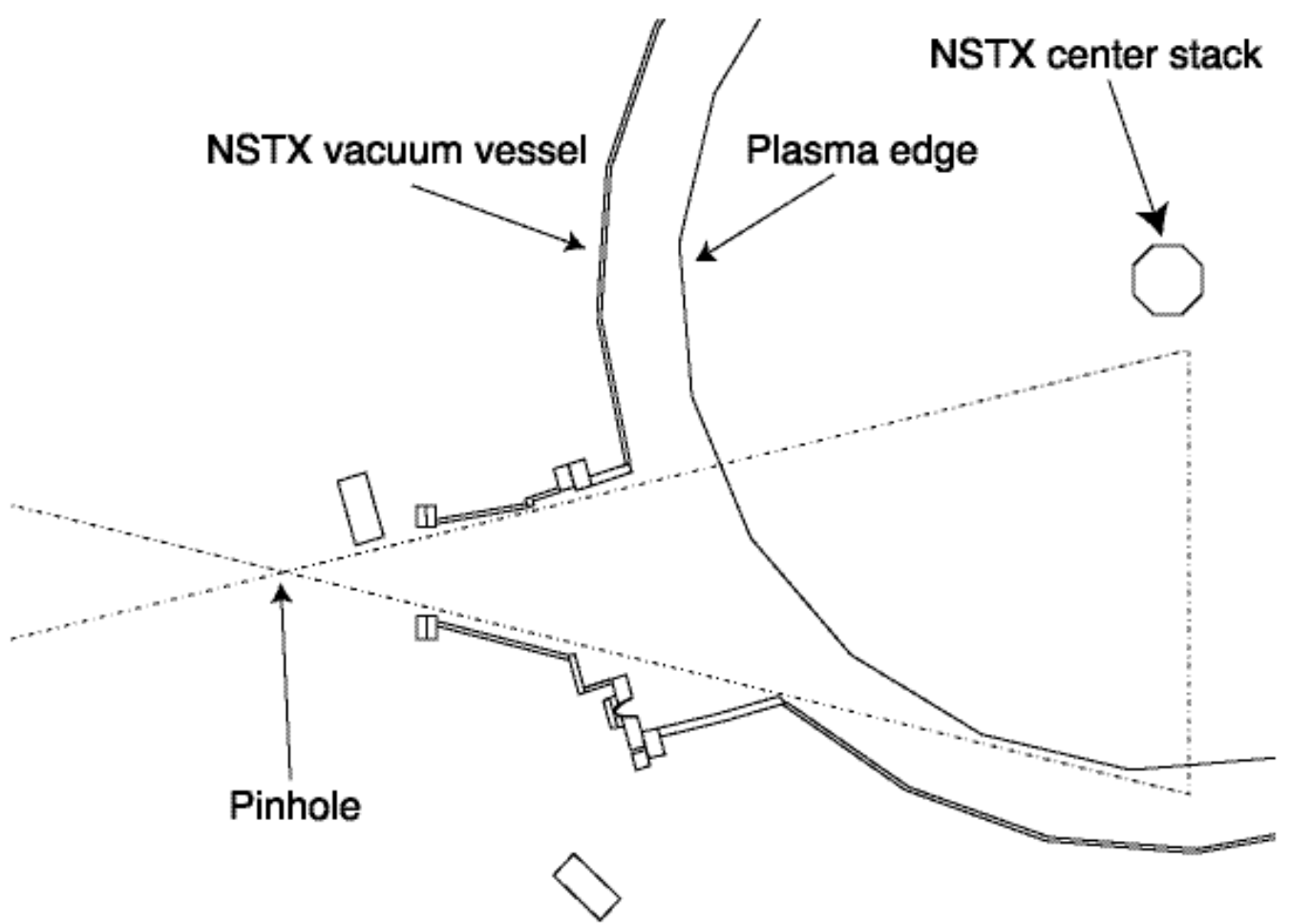

FIG. 2 


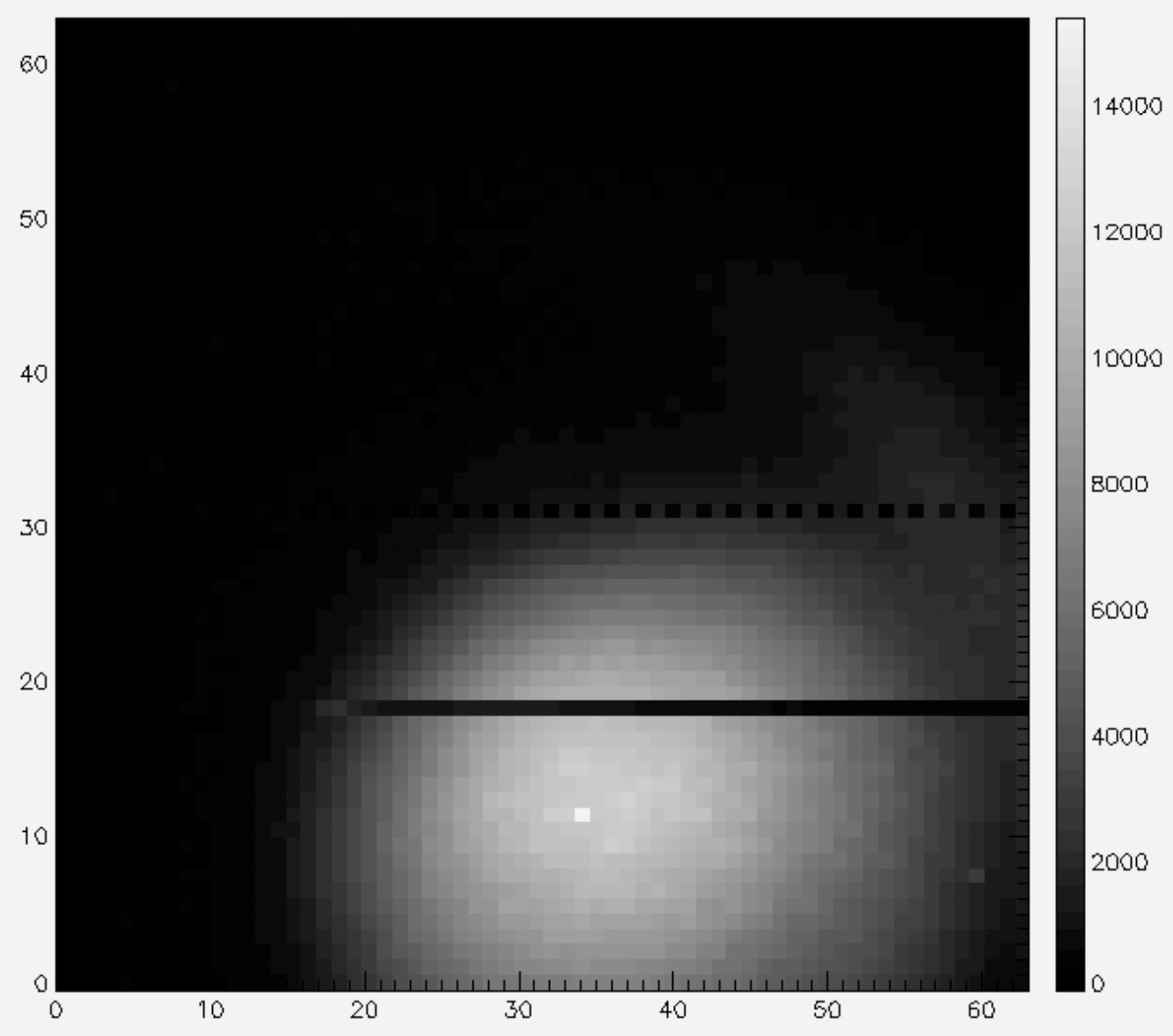

FIG. 3 


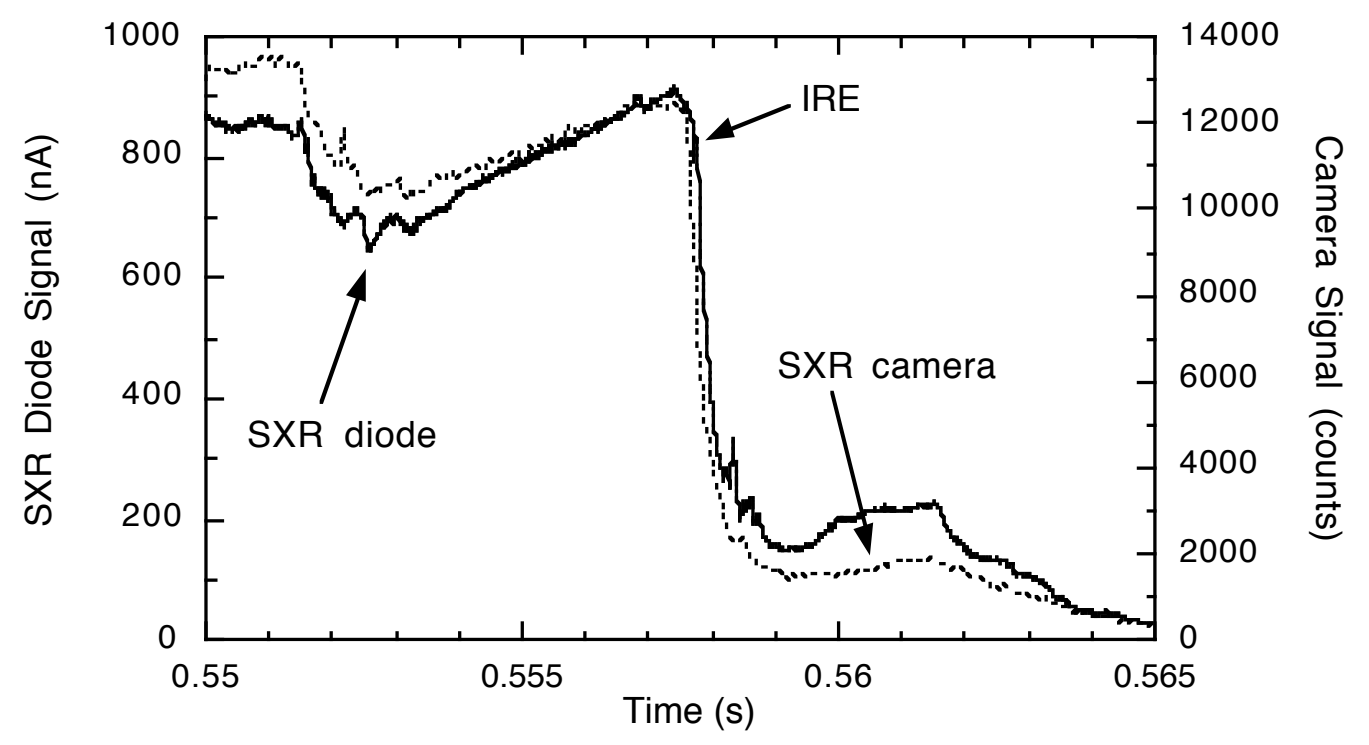

FIG. 4 


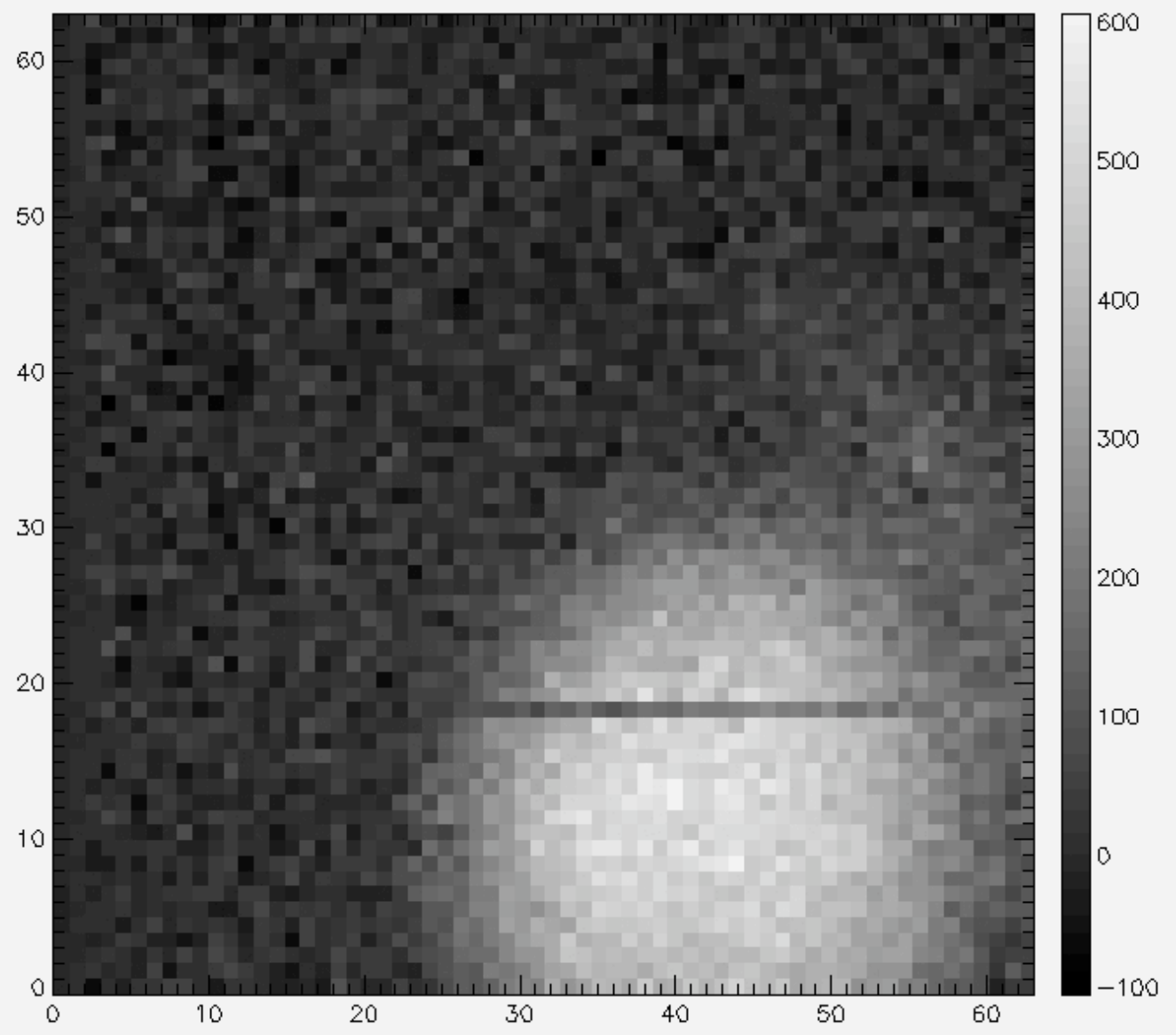

FIG. 5 


\section{External Distribution}

Plasma Research Laboratory, Australian National University, Australia

Professor I.R. Jones, Flinders University, Australia

Professor João Canalle, Instituto de Fisica DEQ/IF - UERJ, Brazil

Mr. Gerson O. Ludwig, Instituto Nacional de Pesquisas, Brazil

Dr. P.H. Sakanaka, Instituto Fisica, Brazil

The Librarian, Culham Laboratory, England

Mrs. S.A. Hutchinson, JET Library, England

Professor M.N. Bussac, Ecole Polytechnique, France

Librarian, Max-Planck-Institut für Plasmaphysik, Germany

Jolan Moldvai, Reports Library, Hungarian Academy of Sciences, Central Research Institute for Physics, Hungary

Dr. P. Kaw, Institute for Plasma Research, India

Ms. P.J. Pathak, Librarian, Institute for Plasma Research, India

Ms. Clelia De Palo, Associazione EURATOM-ENEA, Italy

Dr. G. Grosso, Instituto di Fisica del Plasma, Italy

Librarian, Naka Fusion Research Establishment, JAERI, Japan

Library, Laboratory for Complex Energy Processes, Institute for Advanced Study, Kyoto University, Japan

Research Information Center, National Institute for Fusion Science, Japan

Dr. O. Mitarai, Kyushu Tokai University, Japan

Dr. Jiangang Li, Institute of Plasma Physics, Chinese Academy of Sciences, People's Republic of China

Professor Yuping Huo, School of Physical Science and Technology, People's Republic of China

Library, Academia Sinica, Institute of Plasma Physics, People's Republic of China

Librarian, Institute of Physics, Chinese Academy of Sciences, People's Republic of China

Dr. S. Mirnov, TRINITI, Troitsk, Russian Federation, Russia

Dr. V.S. Strelkov, Kurchatov Institute, Russian Federation, Russia

Professor Peter Lukac, Katedra Fyziky Plazmy MFF UK, Mlynska dolina F-2, Komenskeho Univerzita, SK-842 15 Bratislava, Slovakia

Dr. G.S. Lee, Korea Basic Science Institute, South Korea

Institute for Plasma Research, University of Maryland, USA

Librarian, Fusion Energy Division, Oak Ridge National Laboratory, USA

Librarian, Institute of Fusion Studies, University of Texas, USA

Librarian, Magnetic Fusion Program, Lawrence Livermore National Laboratory, USA

Library, General Atomics, USA

Plasma Physics Group, Fusion Energy Research Program, University of California at San Diego, USA

Plasma Physics Library, Columbia University, USA

Alkesh Punjabi, Center for Fusion Research and Training, Hampton University, USA

Dr. W.M. Stacey, Fusion Research Center, Georgia Institute of Technology, USA

Dr. John Willis, U.S. Department of Energy, Office of Fusion Energy Sciences, USA

Mr. Paul H. Wright, Indianapolis, Indiana, USA 
The Princeton Plasma Physics Laboratory is operated by Princeton University under contract with the U.S. Department of Energy.

\author{
Information Services \\ Princeton Plasma Physics Laboratory \\ P.O. Box 451 \\ Princeton, NJ 08543
}

Phone: 609-243-2750

Fax: 609-243-2751

e-mail: pppl_info@pppl.gov

Internet Address: http://www.pppl.gov 